\title{
The Monetary Policy Change in Turkey in 2009 and Its Implications for Inflation and Growth
}

\author{
K. Kıvanç Karaman* \\ Boğaziçi University
}

\author{
Seçil Yıldırım-Karaman** \\ Istanbul Kemerburgaz University
}

\begin{abstract}
In 2009, the Central Bank of the Republic of Turkey switched from a strict rule-based inflation targeting policy to a discretionary policy aiming for financial stability and growth. This paper investigates the consequences of this policy shift for monetary transmission, inflation rate and economic growth using the Synthetic Control Method. More specifically, the paper presents a counterfactual estimation of the inflation rate and the economic growth in Turkey after 2009. The estimation results suggest that the growth rate would have been similar afterwards, but the inflation rate would have been on average three percentage points lower had the CBRT stuck to the inflation targeting policy. This finding lends support to the argument that for developing countries inflation targeting works as a transparency and credibility tool and improves economic outcomes.
\end{abstract}

Keywords: Turkey, CBRT, monetary policy, synthetic control method, inflation.

JEL codes: E2, E31, E52, E5

\section{Para Politikasında 2009 Yılında Gerçekleșen Değişim ve Enflasyon ve Büyüme Üzerinde Etkileri}

\section{Özet}

TCMB 2009 yılında, kurala bağlı enflasyon hedefleme politikasından finansal istikrar ve büyümeyi de hedefleyen iradi bir politikaya geçmiştir. Bu makale, bu politika değişikliğinin parasal aktarım mekanizması, enflasyon ve büyüme üzerindeki etkilerini Sentetik Kontrol Metodu ile incelemektedir. Bu amaçla, 2009 sonrasında TCMB'nin fiyat istikrarını hedefleyen kurala bağlı politikasına devam ettiği varsayımı altında karşılgusal enflasyon ve büyüme oranları tahmin edilmiştir. Tahmin sonuçları, kurala bağl1 politika devam etseydi, büyümenin değişmemiş, enflasyonun ise ortalamada yüzde üç daha düşük olacağı sonucunu vermektedir. Bu sonuç, gelişmekte olan ülkelerde enflasyon hedeflemesinin bir şeffaflık ve kredibiliteye aracı olarak kullanılabileceği ve iktisadi performansı iyileştireceği görüşünü destekler.

* K. Kıvanç Karaman is an Assistant Professor in the Department of Economics at Boğaziçi University, 34342, Bebek, Istanbul, Turkey. Email: kivanc.karaman@boun.edu.tr

** Seçil Yıldırım-Karaman is an Assistant Professor in the Department of Economics at Istanbul Kemerburgaz University, Mahmutbey, Istanbul, Tukey. Email: secil.yildirim@kemerburgaz.edu.tr 
7 he consequences of inflation-targeting (hereafter IT) regimes have been a major source of debate in the monetary policy literature. The recent experience of the Turkish economy, which went through a shift in policy rule around 2009, closely relates to this debate. The Central Bank of the Republic of Turkey (CBRT) had adopted IT as a monetary policy strategy as a part of the IMF stabilization program in 2001. Under the IT regime CBRT clearly stated an objective range for the inflation rate and rigorously pursued its objective. In 2009, however, CBRT switched from its rule based IT policy to a discretionary policy aiming also for financial stability. In this paper, we present a brief history of monetary policy through this period, investigate the impact of the switch in monetary policy on inflation and growth using the Synthetic Control method, test the effectiveness of the monetary policy before and after the switch, and relate our results to the broader debate in the literature on inflation targeting and rule-based monetary policy.

The changes in policy in Turkey in the late 2000s are discussed in a number of recent papers. Gürkaynak et al. (2015) in their analysis of CBRT's policy rule find a break in 2009. In particular, their structural break tests identify a switch from aggressive interest rate hikes against inflation before 2009 to much milder responses afterwards. They also estimate that had the Central Bank stuck to its strict inflation targeting policy, the interest rates should have been on average 7\% higher after 2009. Acemoğlu and Üçer (2015) and Akkaya and Gürkaynak (2012) put the monetary policy shift in the broader context and argue that in the late 2000s different aspects of economic policy in Turkey took a turn from a rule-based framework towards discretion. While these papers investigate the impact of these policy changes on economic outcomes, they do not account for the effects of the changes in global economic conditions after the financial crisis. Consequently, separating out the effect of abandonment of strict inflation targeting from the effect of changes in global economic conditions requires counterfactual analysis.

The main contribution of this paper is to undertake a counterfactual analysis of the impact of the switch in 2009 from rule-based inflation targeting to a discretionary policy on inflation and real GDP growth. The counterfactual analysis is done using the Synthetic Control Method, first introduced by Abadie et al. (2010) and used to study the effects of particular policy interventions. ${ }^{[1]}$ The method first constructs a synthetic control unit for the treated country by assigning weights to countries from a donor pool to best match the predictor characteristics of the treated country. It then becomes possible to compare the treated country and its synthetic control for the variable of interest and to identify both the direction and the magnitude of the impact of the treatment on this variable. Because the Synthetic Control Method is essentially a generalization of the difference-in differences methodology, it allows controlling for the time-varying cofounding variables, such as the changes in global economic conditions in our paper.

\footnotetext{
[1] Abedie et al. (2015), Meyersson (2016)
} 
The counterfactual estimation results show that had the CBRT stuck to inflation targeting in the post-2010 period, the average inflation rate would have been 3\% lower and real GDP growth would have been similar. The findings remain robust when placebo tests are run and different sets of predictor variables are used. Consequently, the paper provides support for the argument that for Turkey and comparable countries inflation targeting policy improves inflation performance at no cost for growth.

To further substantiate the impact of the abandonment of the inflation targeting policy, the paper also analyzes the response of bond yields to monetary policy decisions before and after the policy switch. For this purpose, we estimate the response of one, two and five-year bond returns to policy surprises for the two sub-periods using an event study approach. The results suggest that bond returns stopped responding to policy surprises after the policy switch. The underlying reason was that any reduction in short-term rates was not consistent with the long-term inflation target which in turn weakened the transmission of policy decisions to financial assets with longer term maturity.

Our findings are consistent with the literature on the benefits of IT strategy. The aim of IT strategy is to achieve long-term price stability and to reduce inflation volatility which in turn helps anchor the private sector's expectations and hence promotes economic growth. Svensson (1997), Mishkin (1999), Bernanke et al. (1999), Bernanke and Mishkin (1997) and Kramer et al. (2008) argue that IT makes the implementation of monetary policy more transparent and increases the credibility of the central bank in the eyes of the public. Mendonça (2007a), Mishkin and Hebbel (2007) and Mendonça and Souza (2012) show that inflation targeting helps reduce inflation rate and inflation volatility. Johnson (2002), Levin, Natalucci and Pieger (2004), and Gürkaynak, Levin and Swanson (2008) suggest that inflation targeting helps anchor inflation expectations. Davig and Gürkaynak (2015) and Orphanides (2013) argue that monetary policy should only focus on price stability rather than other mandates because focusing on other issues makes monetary authority overburdened.

The rest of the paper proceeds as follows: Section 2 discusses the monetary policy in Turkey after 2001. Section 3 investigates the monetary transmission for the periods before and after 2010. Section 4 discusses the methodology and data and presents the results for the counterfactual analysis of the impact of the policy switch using the Synthetic Control method. Section 5 discusses the findings and the last section concludes the paper.

\section{Stance of Monetary Policy in Turkey}

In the beginning of the 2000s Turkey had a high inflation rate around $70 \%$. In 2001, Turkey started to implement a stabilization program supported by the IMF. As a part of this program the CBRT became independent and began to implement inflation targeting. This policy became successful in decreasing the inflation rate to around $10 \%$ by 2006 . Figure 1 displays the evolution of the inflation rate in Turkey after the independence of the CBRT. 
Figure 1

Inflation Rate in Turkey after 2002

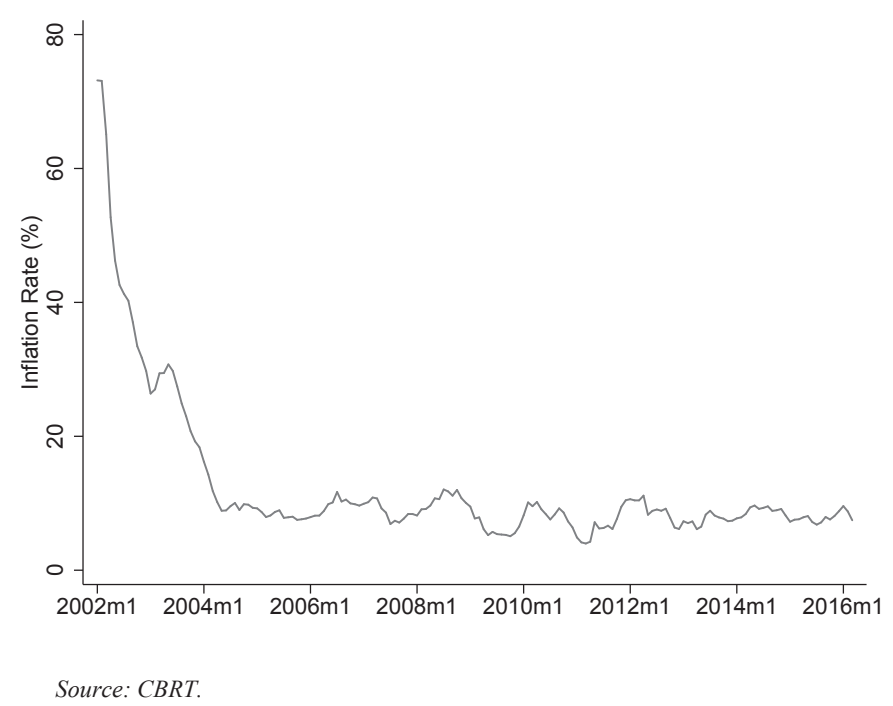

Figure 2 omits the initial four years of the disinflation program and displays the inflation target and the actual inflation rate between 2006 and 2016. The figure shows that in the last ten years the inflation rate has fluctuated around $8 \%$. As such, it stubbornly remained above the target level of $5 \%$ and had a high volatility.

Figure 2

Inflation Rate and Inflation Target in Turkey after 2006

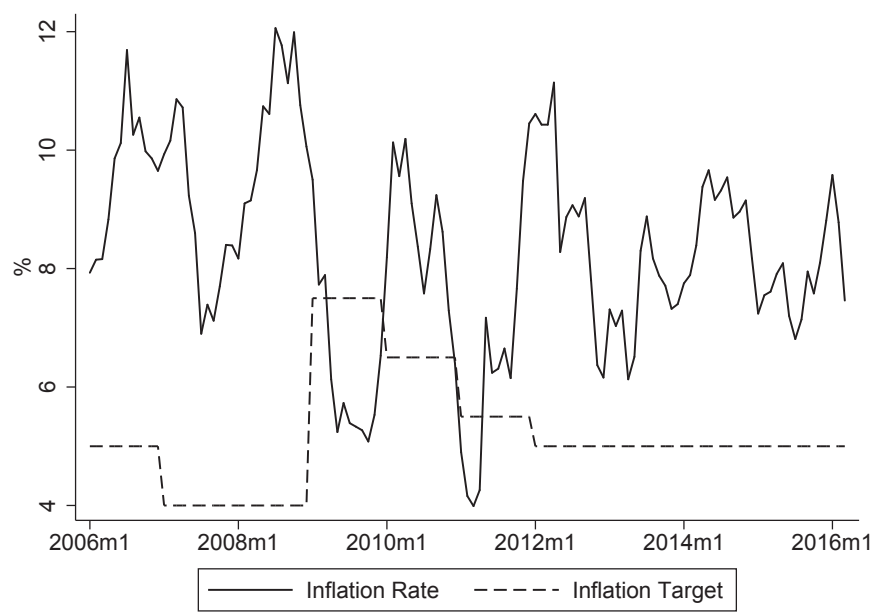

Source: $C B R T$. 
In the aftermath of the global financial crisis in 2008, the CBRT abandoned its strict IT policy. On its official website, the bank lists the new policy tools adopted after the crisis, and states that "With these initiatives, in the framework of its primary objective of price stability, the CBRT has shifted towards a flexible monetary policy, which closely monitors financial stability."[2] Note also that, while other countries also experimented with new tools during the crisis, in the Turkish case the shift in policy was permanent.

Going beyond descriptive evidence, Gürkaynak et al. (2015) formally test the policy rule the CBRT followed after 2001 and find a structural break in 2009. In particular, using a one-week interbank borrowing rate to estimate the reaction function of the CBRT, they find that the CBRT was a strict inflation targeter before 2009 but not after 2009. Accordingly, before 2009, in response to one unit deviation of inflation from its target, the CBRT increased interest rate by $1.3 \%$, whereas after 2009 , the response was only a $0.6 \%$ increase. The paper also estimates the counterfactual interest rate and finds that the interest rate would have been on average 7 percentage points higher had TCMB stuck to its rule-based policy in the post-2010 period.

Beginning in 2010, the CBRT first used the reserve requirements to control the loan growth and then used the volatility of the overnight interest rate ${ }^{[3]}$ to decrease the short-term currency inflows by increasing the risk factor. The latter was an unprecedented policy tool and aimed at containing the current account deficit which had increased significantly after 2002 and was around $-10 \%$ by 2010 .

Fig 3 displays the evolution of the policy rate of the CBRT and o/n interbank borrowing rate after 2006. The policy rate of the CBRT was o/n borrowing rate until May, 2010 and one week repo rate afterwards. The graph shows that until 2010 the market rate closely followed the policy rate whereas after 2010 the two rates do not move together.

Figure 4 displays the CBRT overnight borrowing and lending rates and the o/n interbank borrowing rate. In November 2010 the CBRT started to use the band between the borrowing and lending rates as a policy tool to control the volatility of interest rate. After this date the market rate fluctuated between the CBRT borrowing and lending rates with a high volatility. As the band increased (decreased), the volatility of the market rate also increased (decreased).

\footnotetext{
${ }^{[2]}$ http://www.tcmb.gov.tr/wps/wcm/connect/tcmb+en/tcmb+en/main+menu/monetary+policy/financial+stability/the $+\mathrm{cb}$ $\mathrm{rt}+$ and+financial+stability

[3] CBRT controlled the volatility of the overnight interest rate through controlling the band between borrowing and lending rates. In November 2010 the CBRT increased the band between borrowing and lending rates from 3 to 7 percentage points.
} 
Figure 3

CBRT Policy Rate and O/N Interbank Borrowing Rate

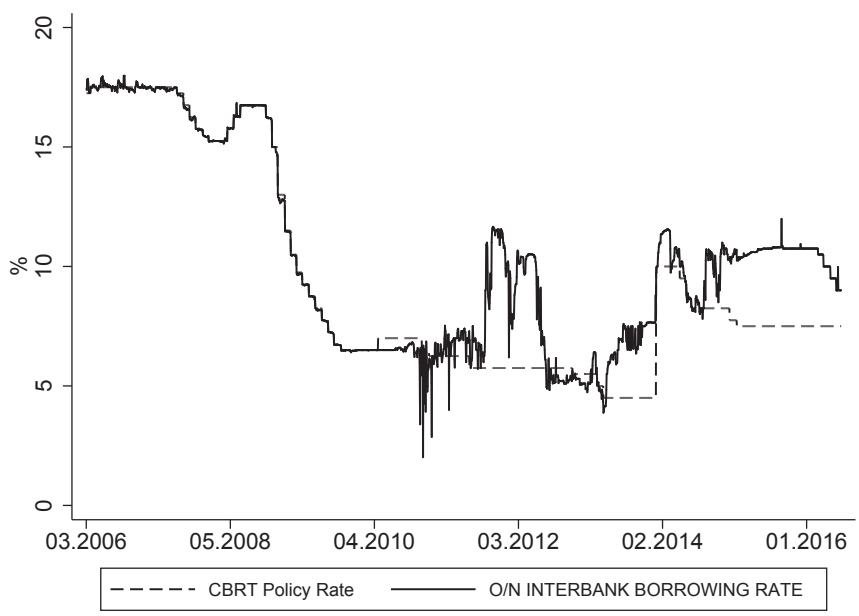

Source: $C B R T$.

Figure 4

CBRT O/N Borrowing and Lending Rates and O/N Interbank Borrowing Rate

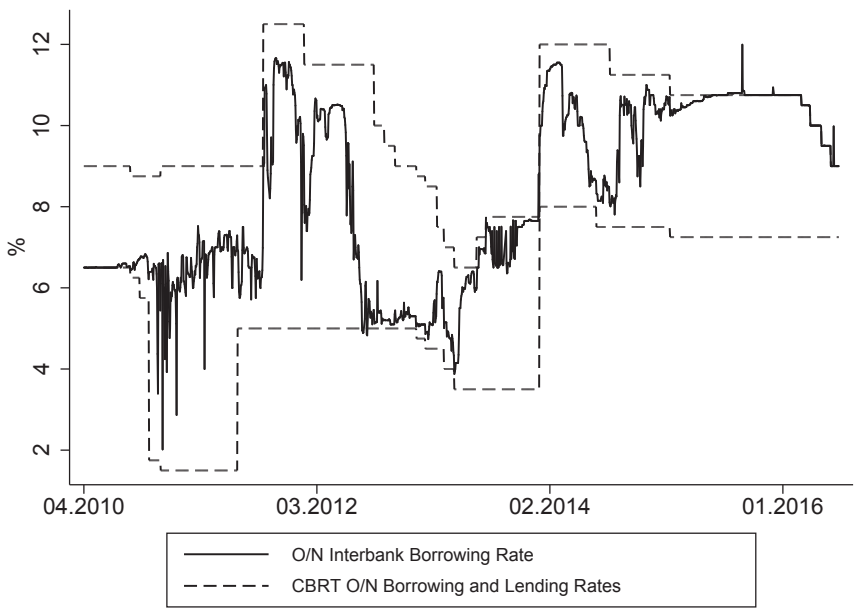

Source: CBRT and Reuters. 
Figure 5 displays the 5 -year bond return and o/n interbank borrowing rate. Accordingly, the short-term interest rates were low and the 5-year bond return was on average 2 percentage points higher than o/n interbank borrowing rate. When the CBRT hiked the short-term interest rates by 5.5 percentage points in January, 2014, the 5-year bond return fell below the short-term interest rates. This finding supports the expectations hypothesis which states that a lower (higher) short-term interest rate induces a higher (lower) inflation expectations which in turn increases (decreases) the long-term interest rates. Another plausible explanation is that lowering the short-term interest rates when the inflation rate is high increases uncertainty for the future which increases the risk premium for the financial assets that have long term maturity. The next section provides a more detailed discussion of the weakening in the monetary transmission after 2010.

Figure 5

\section{5-Year Bond Return and O/N Interbank Borrowing Rate}

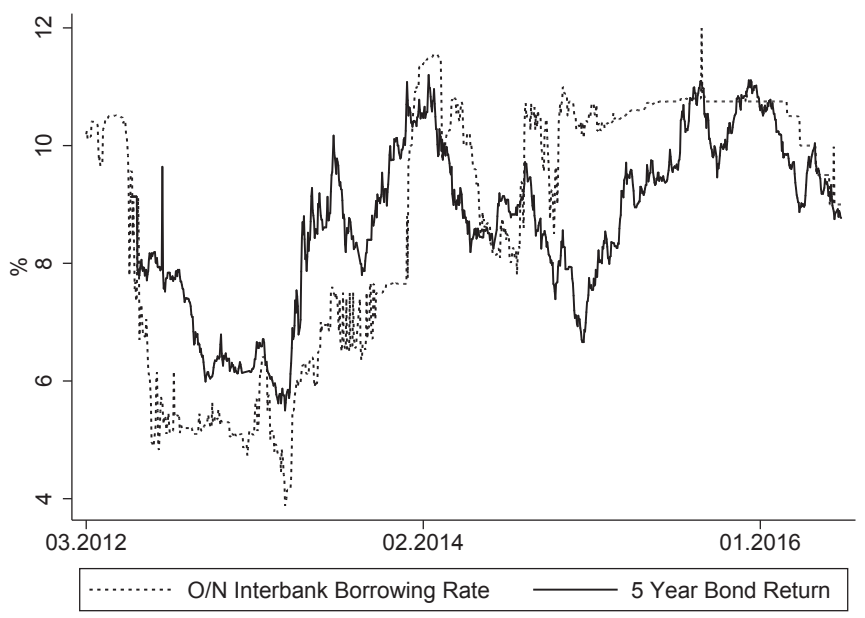

Source: Reuters.

Figure 6 shows the USD/TRY implied volatility which is a measure of financial uncertainty and the long-term bond returns after January, 2016. The figure points to a strong correlation between the long-term interest rates and the implied volatility. We also see a jump in the implied volatility and long-term interest rates in April, 2016 when the governor of the CBRT changed. The figure suggests that the long-term interest rates in Turkey have been more responsive to the perceived uncertainty than the policy decisions about the short-term interest rates. 
Figure 6

\section{Bond Yield and USD/TRY 1M Implied Volatility}

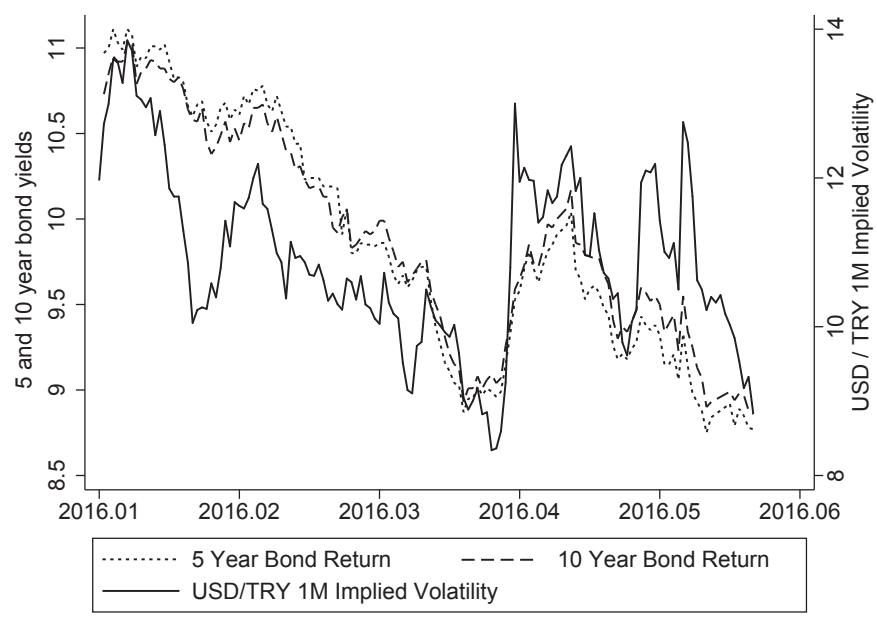

Source: Reuters.

\section{Monetary Transmission before and after 2010}

In order to better interpret the counterfactual estimation in the next section, we first analyze the effectiveness of monetary transmission for the periods before and after 2010. Monetary transmission refers to the process through which policy decisions affect real sector. Its effectiveness depends on the effect of monetary policy on the long-term interest rates because long-term interest rates shape the consumption and investment decisions of the agents. Monetary authority controls the short-term interest rates, which in turn affect the long-term interest rates.

To empirically investigate the effect of the policy shift on the effectiveness of the monetary transmission, we estimate the response of bond returns to the monetary policy decisions before and after the switch in the monetary policy rule. If the long-term bond returns moved in the same direction with the policy decisions, it would follow that the policy decisions of the CBRT were consistent with the long-term inflation target and policy actions were transmitted to the financial markets efficiently. If not, it would imply that policy decisions generated uncertainty about the future prices because they did not follow the long-term inflation target, and monetary transmission was not efficient.

To investigate this impact the following OLS equation is estimated separately for 2006-2010 and 2010-2016 using an event study approach:

$$
\Delta Y_{i t}=\alpha+\beta m p s_{t}+\varepsilon_{t}
$$

where $\Delta Y_{i t}$ is the change in the government bond return with maturity $i$ at time $t$ and $\mathrm{mps}_{\mathrm{t}}$ is the monetary policy surprise at time $\mathrm{t}$. 
To calculate the monetary policy surprise we use the difference between the overnight interbank borrowing rates before and after the policy meeting on the meeting days. Note that in the event study analysis we were not interested in the policy rate announcement itself, but rather the surprise component of the policy rate announcement, and how it affected the bond returns. Consequently, measuring the surprise component of the policy rate announcement required using a short-term market rate which was not decided by the central bank and which priced the expectations for the policy rate announcement before the meeting. The interbank rate satisfied both conditions, as Alp et al. (2010) showed that Turkish Lira Interbank Rate captured the market expectations for monetary policy. The daily data for the government bond returns and overnight TRLIBOR rates were obtained from Reuters. ${ }^{[4]}$

The regression results are summarized in Table 1. The responses of both one- and two-year bond returns to monetary policy surprises are significant before 2010, but the response becomes insignificant after 2010. More specifically, before 2010, one- and two-year bond returns respectively increased by 4.65 and 4.02 percentage points in response to a one percentage point increase in the monetary policy surprise, and these coefficients were significant at the $1 \%$ level. After 2010 , the coefficients of the monetary policy surprises were not significant and $\mathrm{R}^{2}$ values were close to zero. If the equation is estimated for the whole period, the coefficients of the monetary policy surprises are once again insignificant.

Table 1

Response of Bond Returns to Monetary Policy Surprises before and after 2010

\begin{tabular}{|c|c|c|c|c|c|c|c|c|c|}
\hline & \multicolumn{3}{|c|}{$2006-2010$} & \multicolumn{3}{|c|}{$2010-2016$} & \multicolumn{3}{|c|}{ 2006-2016 } \\
\hline & $\begin{array}{l}1 \text { Year } \\
\text { Bond } \\
\text { Return }\end{array}$ & $\begin{array}{c}2 \text { Year } \\
\text { Bond } \\
\text { Return }\end{array}$ & $\begin{array}{c}5 \text { Year } \\
\text { Bond } \\
\text { Return }\end{array}$ & $\begin{array}{l}1 \text { Year } \\
\text { Bond } \\
\text { Return }\end{array}$ & $\begin{array}{c}2 \text { Year } \\
\text { Bond } \\
\text { Return }\end{array}$ & $\begin{array}{c}5 \text { Year } \\
\text { Bond } \\
\text { Return }\end{array}$ & $\begin{array}{l}1 \text { Year } \\
\text { Bond } \\
\text { Return }\end{array}$ & $\begin{array}{l}2 \text { Year } \\
\text { Bond } \\
\text { Return }\end{array}$ & $\begin{array}{c}5 \text { Year } \\
\text { Bond } \\
\text { Return }\end{array}$ \\
\hline \multirow{2}{*}{$\begin{array}{l}\text { Constant } \\
\text { term }\end{array}$} & 17.77 & 19.27 & 17.44 & 8.39 & 8.43 & 8.66 & 11.48 & 11.97 & 11.52 \\
\hline & $(0.75)$ & $(0.78)$ & $(0.67)$ & $(0.20)$ & $(0.18)$ & $(0.24)$ & $(0.52)$ & $(0.58)$ & $(0.48)$ \\
\hline \multirow{2}{*}{$\begin{array}{c}\text { Monetary } \\
\text { Policy } \\
\text { Surprise }\end{array}$} & $4.02 * * *$ & $4.65^{* * * *}$ & 1.96 & 0.38 & 0.36 & 0.33 & 0.10 & 0.05 & -0.38 \\
\hline & $(1.42)$ & $(1.47)$ & $(1.24)$ & $(0.31)$ & $(0.28)$ & $(0.24)$ & $(0.88)$ & $(0.98)$ & $(0.82)$ \\
\hline $\mathrm{R}^{2}$ & 0.20 & 0.23 & 0.07 & 0.02 & 0.03 & 0.03 & 0.00 & 0.00 & 0.00 \\
\hline
\end{tabular}

Standard deviations are in parenthesis

${ }^{[4]}$ Interbank rate is a better fit for our purposes than the weighted average cost of the CBRT funding because we are interested in finding a proxy to measure the surprise component of the policy decision. Weighted average cost of the CBRT funding does not price the market expectations as it is a policy tool set by the CBRT whereas interbank rate prices the expected policy decision before the policy announcement. 
These findings suggest that before 2010 one- and two-year bond returns moved along with the policy rate and so the policy decisions of the CBRT were consistent with the long-term inflation target. After 2010, however, the CBRT did not adjust short-term rates in response to the fluctuations in the inflation rate, which in turn decreased the credibility of the CBRT and increased uncertainty about the future price level. In the absence of a strict inflation target, agents arguably perceived reductions in the short-term interest rates as an inflation threat for the future. This in turn weakened the transmission of policy decisions to financial markets and real sector.

The results also suggest that positive monetary policy surprises made the yield curve flatter before 2010, as the estimated effect on the five-year bond return was insignificant. This finding is consistent with the expectations hypothesis. Because the policy decisions were consistent with the long-term inflation target before 2010, an increase in the policy rate reduced long-term inflation expectations. The lower expectations in turn caused a decline in the expected short-term rates and therefore five-year bond returns did not respond to policy surprises.

It is not possible, however, to reach a conclusive verdict on the impact of the shift in the TCMB's monetary policy just by analyzing Turkish data. Because global economic conditions changed with the financial crisis, the change in the monetary transmission that we identify might at least be partly due to these changes. Separating out the impact of the monetary policy shift from the changes in global economic conditions requires a counterfactual analysis, which we undertake in the next section.

\section{Synthetic Control Estimation}

\section{Methodology and Data}

For the counterfactual analysis of the impact of the abandonment of strict inflation targeting, the paper uses the Synthetic Control Method which was first introduced by Abadie et al. (2010) ${ }^{[5]}$ and was recently used in comparative case studies to investigate the effects of particular policy interventions. The Synthetic Control Method removes the ambiguity in the comparative case studies about the choice of comparison units. In particular, in the model, the synthetic control unit is constructed as the weighted average of countries from a donor pool and the weights are chosen endogenously so that the synthetic control unit best approximates the predictor characteristics of the treated unit.

In this paper the method is used to construct a synthetic control unit for Turkey and to estimate the impact of the policy shift by comparing the inflation and growth performance of Turkey and its control after 2009. Because Turkey and its synthetic control are both affected by the same global economic shocks, the estimated difference in their performance is not due to these shocks. In constructing the synthetic control unit for Turkey's inflation performance, pre-2009 values of household consumption to GDP ratio, real GDP growth, and previous values of inflation rate are used as predictors. For

${ }^{[5]}$ See appendix for technical details. 
the synthetic control unit for Turkey's growth performance, the predictors are pre-2009 values of investment to GDP ratio, real GDP growth, household consumption to GDP ratio and government spending to GDP ratio. The synthetic control unit is constructed by choosing countries from a donor pool of 38 countries. Because our focus in this paper is on monetary policy, we choose to run the model with quarterly data, and as a result, relatively underdeveloped countries with data availability issues cannot be included in the donor pool. Note, however, countries lacking quarterly data are unlikely to match Turkey's predictor characteristics in the first place, and so their omission is unlikely to affect the results. The sample covers 2004Q1 to 2015Q4. The years before 2004, in the aftermath of the 2000-2001 crisis and with a stabilization program in place, are left out. The data used in the analysis is taken from the International Financial Statistics database. Based on Gürkaynak et al. (2015), 2009Q2 is chosen as the break point in the policy rule of the CBRT, and synthetic control values are estimated for the period after this date.

Leaving the technical details to the appendix, the estimation method can be summarized as follows: Suppose that Turkey is the first country in the sample. $Y_{1 t}^{N}$ is the outcome observed in Turkey at time $\mathrm{t}$ when there is no policy intervention. $Y_{1 t}^{I}$ is the observed outcome for Turkey between 2009Q2 and 2015Q4 when Turkey is exposed to policy intervention. $Y_{i t}^{N}$ is the outcome that would be observed if there were no policy shift. The effect of intervention for Turkey can be calculated as:

$$
\alpha_{1 \mathrm{t}}=Y_{1 t}^{I}-Y_{1 t}^{N}
$$

The aim of the model is to estimate $Y_{1 t}^{N}$ for the periods after the policy shift. To estimate $Y_{1 t}^{N}$, the following factor model is estimated for each country in the donor pool:

$$
Y_{i t}^{N}=\delta_{\mathrm{t}}+\theta_{\mathrm{t}} \mathrm{Z}_{\mathrm{i}}+\lambda_{\mathrm{t}} \mu_{\mathrm{i}}+\varepsilon_{\mathrm{it}}
$$

$\delta_{\mathrm{t}}$ is an unknown common factor with constant factor loadings across countries, $Z_{\mathrm{i}}$ is a vector of observed covariates which are not affected by the intervention, $\theta_{t}$ is a vector of unknown parameters, $\lambda_{\mathrm{t}}$ is a vector of unobserved common factors, $\mu_{\mathrm{i}}$ is a vector of unknown factor loadings, and $\varepsilon_{i t}$ is the error term.

A particular $\mathrm{W}^{*}=\left(w^{*}, \ldots \ldots w^{*}{ }_{j+1}\right)$ is determined so that the difference between the pre-intervention characteristics of Turkey and a synthetic control is minimized. In particular, $\mathrm{X}_{1}$ is the $k \times 1$ vector of the pre-intervention characteristics of Turkey, and $\mathrm{X}_{0}$ is the $k \times J$ matrix of the same variables for the control countries. Following Abadie et al. (2010) $\mathrm{W}^{*}$ is the value of $\mathrm{W}$ that minimizes:

$$
\sum_{m=1}^{k}\left(X_{1 m}-W X_{0 m}\right)^{2}
$$

The synthetic control for Turkey at period $t$ is the weighted average of the estimated outcomes of the countries in the donor pool:

$$
Y_{1 t}=\sum_{j=2}^{j+1} w_{j}^{*} y_{j t}
$$




\section{Counterfactual Estimation for the Inflation Rate after 2010}

In this section, we present the counterfactual estimation results for the effect of the abandonment of strict inflation targeting in 2009 on the inflation rate in the subsequent period using the Synthetic Control Method.

Table 2 shows the weights of different countries used in constructing the synthetic control unit for Turkey for the inflation counterfactual. Accordingly, the synthetic control for Turkey is the weighted average of Costa Rica, Hungary, Moldova, Ecuador, Indonesia and Denmark. These countries are similar to Turkey in that they are middle income, have inflation rates ranging between $3 \%$ to $14 \%$, have relatively weak institutions, and are prone to political instability. Only Denmark, which has the smallest weight, stands out with its developed economy and stable political system. Note, however, that the synthetic control method does not identify individual countries that match Turkey's characteristics, but rather identifies a set of countries whose weighted average matches Turkey, and the finding suggests a small weight of Denmark improves the overall match between Turkey and its synthetic control.

Table 3 compares the values of predictors for Turkey and its synthetic control. The table shows that the average values of predictors for Turkey and its control are very close, suggesting that synthetic Turkey matches Turkey well.

Table 2

Weights of the Countries in Synthetic Turkey

(for the counterfactual inflation rate estimation)

\begin{tabular}{l|l|l|l}
\hline Country & Weight & Country & Weight \\
\hline Argentina & 0 & Italy & 0 \\
\hline Australia & 0 & Japan & 0 \\
\hline Austria & 0 & Latvia & 0 \\
\hline Brazil & 0 & Malaysia & 0 \\
\hline Canada & 0 & Mexico & 0 \\
\hline Chile & 0 & Moldova & 0.201 \\
\hline Colombia & 0 & Netherlands & 0 \\
\hline Costa Rica & 0.452 & New Zealand & 0 \\
\hline Croatia & 0 & Norway & 0 \\
\hline Czech Republic & 0 & Peru & 0 \\
\hline Denmark & 0.015 & Philippines & 0 \\
\hline Ecuador & 0.071 & Poland & 0 \\
\hline France & 0 & Portugal & 0 \\
\hline Germany & 0 & South Africa & 0 \\
\hline Greece & 0 & Spain & 0 \\
\hline Hungary & 0.21 & Sweden & 0 \\
\hline Iceland & 0 & Switzerland & 0 \\
\hline Indonesia & 0.051 & Thailand & 0 \\
\hline Israel & 0 & United Kingdom & 0 \\
\hline & & &
\end{tabular}


Table 3

Means of the Predictors in the Treated Country and Synthetic Control Units (for the counterfactual inflation rate estimation)

\begin{tabular}{l|l|l}
\hline Predictor & Treated & Synthetic \\
\hline Household Consumption to GDP Ratio (2005 average) & 0.720297 & 0.721821 \\
\hline Household Consumption to GDP Ratio (2006 average) & 0.710199 & 0.711323 \\
\hline Household Consumption to GDP Ratio (2007 average) & 0.714554 & 0.712002 \\
\hline Real GDP Growth (2006 average) & 6.929343 & 6.403072 \\
\hline Real GDP Growth (2007 average) & 4.81838 & 5.301012 \\
\hline Inflation Rate (2005 average) & 10.14555 & 10.07954 \\
\hline Inflation Rate (2006 average) & 9.586607 & 9.522783 \\
\hline Inflation Rate (2007 average) & 8.782028 & 8.843247 \\
\hline & &
\end{tabular}

We can further divide the period after 2009 in two subperiods. The subperiod between 2009Q3 and 2010Q4 is the recovery from the financial crisis. Through this subperiod many central banks implemented extraordinary policies to contain the negative consequences of the global financial crisis. Turkey's economy recovered in the subperiod after 2011. As Figure 9 shows the actual real GDP in Turkey was no longer lower than its trend after 2011. Hence, we are mainly interested in analyzing the effect of the policy shift after 2011.

The estimated effect of the switch in the monetary policy regime is given by the difference between the synthetic and actual inflation rates which are presented in Figure 7. The actual inflation rate in Turkey fluctuated around $8 \%$ after 2011 . The estimation results suggest that the inflation rate in Turkey would have been around $5 \%$ had the CBRT stuck to IT policy. In other words the abandonment of IT policy permanently increased the inflation rate by about $3 \%$ after the recovery from the financial crisis. This difference between the synthetic and actual values seems to be increasing towards 2015 .

Figure 7

Actual and Synthetic Inflation Rates for Turkey

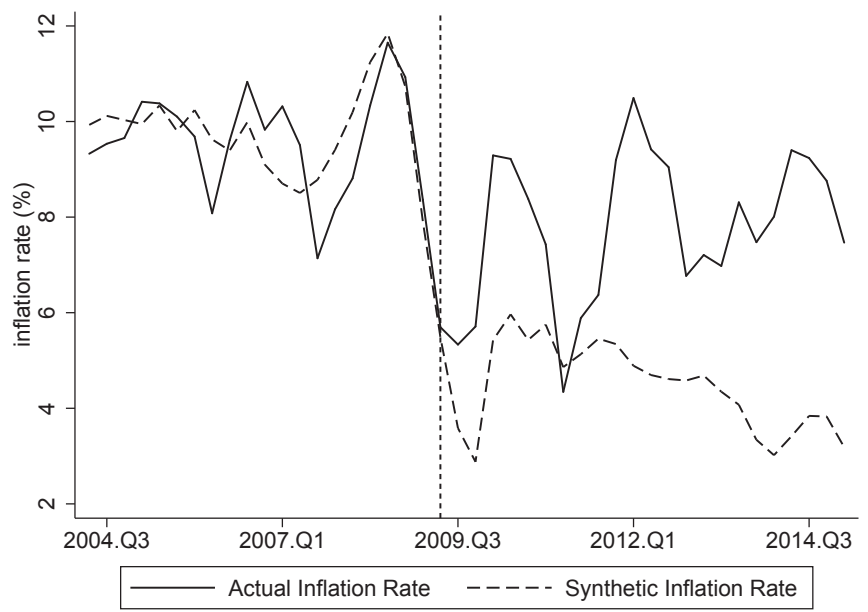


To investigate the robustness of this finding, we ran placebo tests. In placebo tests, for each country in the donor pool, Synthetic Control analysis was conducted as if the country had received the policy intervention, and the effect of this placebo intervention was estimated. Repeating the placebo Synthetic Control analysis for all countries in the donor pool resulted in a distribution of placebo effects. If the estimated effect for Turkey was large relative to the distribution of placebo effects, it was unlikely that the effect was observed by chance, and the placebo tests lended credence to the argument that the policy shift in Turkey had a significant impact.

The results of the placebo test are displayed in Figure 8. Gray lines show the difference between the inflation rate and its respective synthetic value for each country in the donor pool.

The black line represents the estimated difference for Turkey. Before the policy switch the gap fluctuated around zero with an average value of $-0.17 \%$, whereas after the switch it had an average value of $3.33 \%$. The figure shows that the estimated gap for Turkey was large compared to the distribution of the gaps for the countries in the donor pool in the post-2009 period, lending credibility to the results.

As a second robustness check the estimation was repeated using a different set of predictors for the inflation rate. More specifically, the synthetic inflation rate was estimated including government spending to GDP ratio and appreciation/depreciation of domestic currency as predictors and excluding household consumption to GDP ratio and real GDP growth from the set of predictor variables. The results are similar for this new specification as the synthetic inflation rate for the period after 2011 is on average 3.3 percentage points lower than the actual inflation rate. Placebo results for this specification are also similar to Figure 8, providing support for the empirical findings.

Figure 8

\section{Placebo Test}

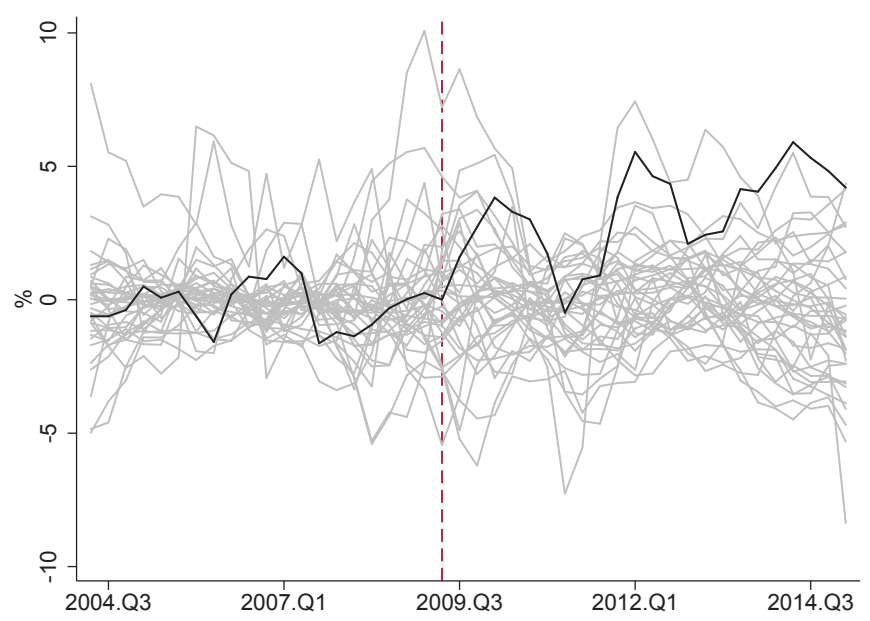




\section{Counterfactual Estimation for the Real GDP growth after 2010}

This section investigates the effect of the policy shift on economic growth. Figure 9 displays the fluctuations of real GDP around its trend after 2000. Real output contracted by $4.8 \%$ in 2009 due to the global financial crisis. Following this contraction the CBRT shifted its focus to economic growth and reduced the overnight borrowing and lending rates respectively to $6.5 \%$ and $9 \%$. The aim of the monetary easing was to reduce the financial distress and to cushion the negative effects of the global financial crisis on economic activity.

As Figure 9 shows after 2010 output was no longer below its trend and the inflation rate continued to fluctuate around $8 \%$. However, the focus of the CBRT in this period was to control the short-term currency inflows and reduce the current account deficit rather than to control the inflation rate or output gap.

Figure 9

Cycles of Real GDP.

Trend of Real GDP is estimated with HP filter

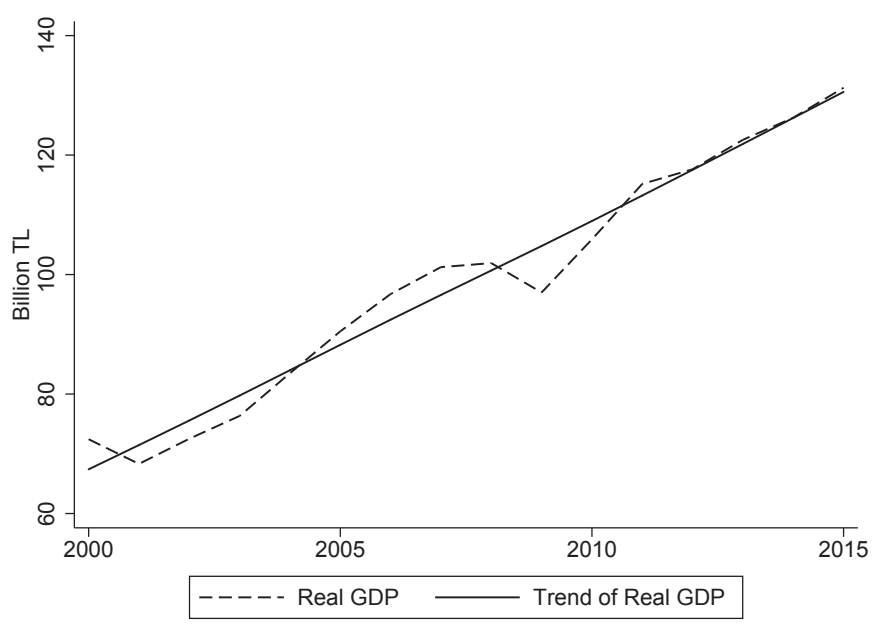

Table 4 shows the weights of countries used to construct the synthetic control for Turkey. The Synthetic Control method finds that a weighted average of Argentina, Hungary, Ecuador and Latvia best approximates the predictor characteristics of Turkey. All of these countries are middle-income economies with relatively weak institutions, like Turkey. Table 5 compares the average values of predictor variables for Turkey and its synthetic control. The table shows a close match, suggesting synthetic Turkey approximates Turkey well. 
Table 4

Weights of the countries in Synthetic Turkey

(for the counterfactual growth rate estimation)

\begin{tabular}{l|l|l|l}
\hline Country & Weight & Country & Weight \\
\hline Argentina & 0.455 & Italy & 0 \\
\hline Australia & 0 & Japan & 0 \\
\hline Austria & 0 & Latvia & 0.124 \\
\hline Brazil & 0 & Malaysia & 0 \\
\hline Canada & 0 & Mexico & 0 \\
\hline Chile & 0 & Moldova & 0 \\
\hline Colombia & 0 & Netherlands & 0 \\
\hline Costa Rica & 0 & New Zealand & 0 \\
\hline Croatia & 0 & Norway & 0 \\
\hline Czech Republic & 0 & Peru & 0 \\
\hline Denmark & 0 & Philippines & 0 \\
\hline Ecuador & 0.182 & Poland & 0 \\
\hline France & 0 & Portugal & 0 \\
\hline Germany & 0 & South Africa & 0 \\
\hline Greece & 0 & Spain & 0 \\
\hline Hungary & 0.238 & Sweden & 0 \\
\hline Iceland & 0 & Switzerland & 0 \\
\hline Indonesia & 0 & Thailand & 0 \\
\hline Israel & 0 & United Kingdom & 0 \\
\hline & & &
\end{tabular}

Table 5

Means of the Predictors in the Treated Country and Synthetic Control Units (for the counterfactual growth rate estimation)

\begin{tabular}{l|l|l}
\hline Predictor & Treated & Synthetic \\
\hline Investment to GDP Ratio (2005 average) & 0.2108673 & 0.2110618 \\
\hline Investment to GDP Ratio (2006 average) & 0.223127 & 0.2207204 \\
\hline Investment to GDP Ratio (2007 average) & 0.214753 & 0.2286225 \\
\hline Investment to GDP Ratio (2008 average) & 0.203362 & 0.2042911 \\
\hline Real GDP Growth (2005 average) & 8.411612 & 7.04572 \\
\hline Real GDP Growth (2006 average) & 6.929343 & 7.006221 \\
\hline Real GDP Growth (2007 average) & 4.81838 & 5.418558 \\
\hline Household Consumption to GDP Ratio (2006 average) & 0.710199 & 0.6431859 \\
\hline Government Spending to GDP Ratio (2006 average) & 0.1230228 & 0.1123955 \\
\hline
\end{tabular}


Figure 10 presents the main result, the actual quarterly growth rate of Turkey and the estimated growth rate of its synthetic control after 2010. Actual real GDP growth is more volatile during the financial crisis and is very close to its synthetic counterpart after 2011. The results suggest that the switch in the policy rule of the CBRT did not have a significant effect on the economic growth performance after the output gap was closed. In other words, abandonment of IT policy, which in the previous section was shown to have increased inflation by $3 \%$, did not improve growth performance. When the estimation is repeated using a different set of predictors as a robustness check, the results are similar. Likewise, Meyersson (2016), who also uses the Synthetic Control Method but with annual data and a different set of predictors, finds that Turkey's growth performance does not diverge from its synthetic control.

Figure 10

\section{Actual and Synthetic Real GDP Growth Rates for Turkey}

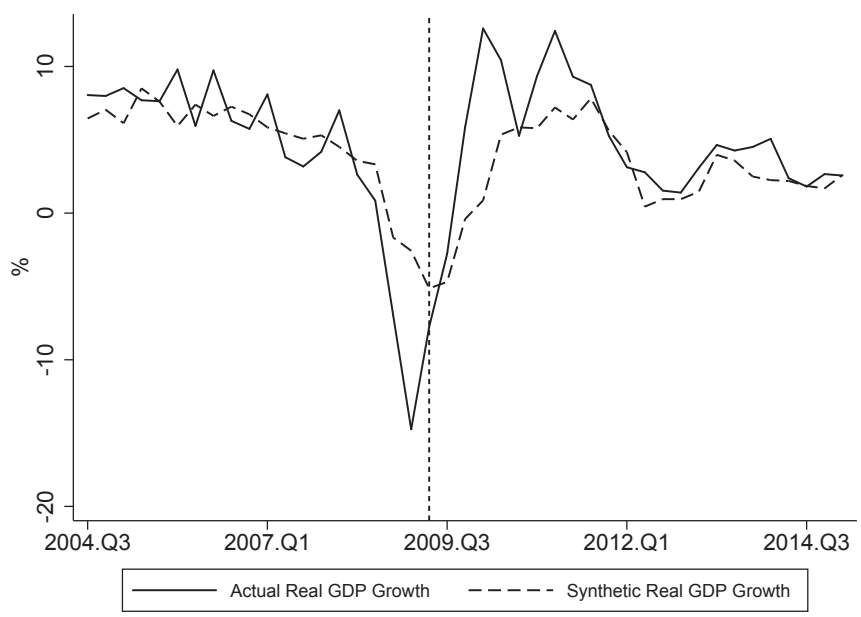

\section{Interpreting the Results}

The results of the counterfactual analysis suggest that Turkey's abandonment of a strict IT policy after 2009 increased inflation rate but did not improve the growth performance. There may be several explanations for this finding. For one, if monetary policy were tight after the recovery from the financial crisis, inflation expectations and the exchange rate would have been under control and this would in turn reduce the price level uncertainty and financial distress. Lower uncertainty would in turn affect output positively and compensate the short-run reduction in the total demand and output caused by the monetary contraction. Alternatively, if the interest rate were higher, it would have attracted higher capital inflows after 2009, which would in turn affect the exchange rate and inflation dynamics and would promote economic growth. Testing alternative explanations and identifying the exact mechanism underlying this result is beyond the scope of this paper, however. 
More broadly, our empirical results are in line with the theoretical work on the implications of IT policy and the costs of specifying objectives other than the inflation rate. Bernanke and Mishkin (1997) point out that focusing on inflation targeting brings coherence, transparency and discipline to monetary policy. Issing (2004) argues that keeping inflation rate at low levels is also a prerequisite for long term growth and efficient allocation of resources. Orphanides (2013) argues that monetary policy will be overburdened if central banks focus on the objectives other than price stability such as employment, fiscal sustainability, and financial stability. Davig and Gürkaynak (2015) theoretically show that focusing more mandates is problematic for central banks because central banks have a single policy tool and there are other policy makers in the economy like government that has more appropriate policy tools for cyclical issues. Using a New Keynesian framework they show that if central banks are charged with a lot of mandates, welfare losses in response to adverse shocks increase.

One caveat in interpreting the results is that the shift in monetary policy towards discretion in the late 2000 s coincided with similar shifts towards discretion in other aspects of economic policy, including the budget process, procurement procedures and regulatory policies (Acemoğlu and Üçer, 2015). The Synthetic Control Method does not give a conclusive answer as to whether and how much these other discretionary policy shifts contributed to the empirical results. Arguably, a monetary policy shift was the main driver of the inflation performance, whereas growth performance might have been affected by these other discretionary policies. All in all, a more cautious interpretation of our result would be that discretionary economic policy worsens the inflation-growth trade-off.

As for the external validity of results, it is important note that the findings are based on a comparison of Turkey and countries with similar characteristics. More specifically, the result should be interpreted to apply to developing countries with moderate to high levels of inflation and who are prone political instability. For these countries, the benefits of IT policy and the anchor it provides might be greater than its benefits for developed countries with low levels of inflation and strong political institutions.

\section{Conclusion}

This paper investigates the effects of the change in the policy rule of TCMB in 2009 on inflation and economic growth. We use the Synthetic Control Method to undertake a counterfactual analysis of the implications of the policy shift. The analysis suggests that abandoning inflation targeting resulted in a similar growth rate and a higher inflation rate relative to comparable countries. This finding supports the view that lack of transparency and commitment in monetary policy might be counterproductive and increase inflation without increasing the growth rate.

Methodologically, the contribution of the paper is to apply the Synthetic Control Method, a relatively recent econometric tool, to evaluate the impact of the monetary policy shift. The method allows constructing a control unit for Turkey as a weighted average of other countries based on objectively defined criteria, and permits counter- 
factual analysis. For the particular policy shift that we try to understand, undertaking a counterfactual analysis is important because the policy shift coincided with the changes in global economic conditions. This is because the counterfactual analysis allows controlling for the global economic shocks common to all countries and separates out the effect of the policy shift.

In the broader context, the findings of the paper relate to the debates in the literature on the rule based versus discretionary decision-making in monetary policy and on the merits of inflation targeting. In this debate, the evidence we find in Turkey supports rule based policy and inflation targeting. It is also worth noting that most studies in support of the benefits of inflation targeting were based on evidence before the Global Financial Crisis, and in the current study, we find that that they hold in the aftermath of the crisis, too.

\section{References}

Abadie, A., Diamond, A., and Hainmueller, J. (2010). "Synthetic Control Methods for Comparative Case Studies: Estimating the Effect of California's Tobacco Control Program," Journal of the American Statistical Association, 105(490): 493-505.

------, (2015). “Comparative Politics and the Synthetic Control Method," American Journal of Political Science, 59(2): 495-510.

Acemoğlu, D. and Uçer, M. (2015). "The Ups and Downs of Turkish Growth, 2002-2015: Political Dynamics, the European Union and the Institutional Slide," National Bureau of Economic Research, No. w21608.

Alp, H., Gürkaynak, R.S., Kara, H., Keleş, G., and Orak, M. (2010). “Türkiye'de Piyasa Göstergelerinden Para Politikası Beklentilerinin Ölçülmesi," (Measuring Monetary Policy Expectations Using Market Indicators in Turkey), İktisat İsletme ve Finans, 25(295): 21-45.

Akkaya, Y., and Gürkaynak, R.S. (2012). "Cari Açık, Bütçe Dengesi, Finansal İstikrar ve Para Politikası: Heyecanlı Bir Dönemin İz,” (Current Account Deficit, Budget Balance, Financial Stability and Monetary Policy: The Mark of a Stormy Period," İktisat İşletme ve Finans, 27(315): 93-119.

Bernanke, B.S. and Mishkin, F.S. (1997). "Inflation Targeting: A New Framework for Monetary Policy?" The Journal of Economic Perspectives, 11(2): 97-116.

Bernanke, B.S., Laubach, T., Mishkin, F.S., and Posen, A.S. (1999). Inflation Targeting: Lessons from the International Experience Princeton. University Press, Princeton.

Davig, T. and Gürkaynak, R.S. (2015). “Is Optimal Monetary Policy Always Optimal?” International Journal of Central Banking, 11: 353-384.

De Mendonça, H.F. (2007a). "Empirical Evidence from Fourteen Countries with Explicit Inflation Targeting," Applied Economics Letters, 14 (8), 573-576.

De Mendonça, H.F., e Souza, G.J.D.G. (2012). "Is İnflation Targeting a Good Remedy to Control Inflation?" Journal of Development Economics, 98(2): 178-191.

Gürkaynak, R.S., Kantur, Z., Taş, M.A., and Yıldırım-Karaman, S. (2015). "Monetary Policy in Turkey after Central Bank Independence," Iktisat Isletme ve Finans, 30(356): 09-38.

Gürkaynak, R.S., Levin, A., and Swanson, E. (2010). "Does İnflation Targeting Anchor Long-run Inflation Expectations? Evidence from the US, UK and Sweden," Journal of European Economic Association 8(6): 1208-1242. 
Issing, O. (2004). "Inflation Targeting: A View from the ECB," Federal Reserve Bank of St. Louis Review, 86(4): 169-179.

Johnson, D.R. (2002). "The Effect of Inflation Targeting on the Behavior of Expected Inflation: Evidence from an 11 Country Panel," Journal of Monetary Economics 49 (8), 1521: 1538.

Kramer, M., Brill, H., Peck, C., Cummings, J., and Jansen, D.J. (2008). “Central Bank Communication and Monetary Policy: A Survey of Theory and Evidence," Journal of Economic Literature, 46 (4): 910-945.

Levin, A.T., Natalucci, F.N., and Piger, J.M. (2004). "The Macroeconomic Effects of Inflation Targeting," Federal Reserve Bank of St. Louis Review, 86(4): 51-80.

Meyersson, E. (2016). “'Pious Populists at the Gate,' A Case Study of Economic Development in Turkey under AKP,” Working Paper.

Mishkin, F.S. (1999). "International Experiences with Different Monetary Policy Regimes," Journal of Monetary Economics, 43(3): 576-606.

Mishkin, F.S., Schmidt-Hebbel, K. (2007). “Does Inflation Targeting Make a Difference?” NBER Working Paper, 12876

Orphanides, A. (2013). “Is Monetary Policy Overburdened?” BIS Papers, No. 435.

Svensson, L.E.O. (1997). "Inflation Forecast Targeting: Implementing and Monitoring Inflation Targets,” European Economic Review, 41(6): 1111-1146. 


\section{Appendix}

The estimation method can be summarized as follows: Suppose that there are $\mathrm{J}+1$ countries and the first country is exposed to the policy intervention. In this case the $\mathrm{J}$ countries are the potential control countries. Suppose periods are denoted by $t=1, \ldots ., \mathrm{T}$ and $\mathrm{T}_{0}$ is the number of pre-intervention periods, where $1 \leq \mathrm{T}_{0}<\mathrm{T}$. $Y_{i t}^{N}$ is the outcome observed in country at time $\mathrm{t}$ when there is no policy intervention. $Y_{i t}^{I}$ is the outcome for country $i$ between $\mathrm{T}_{0}+1$ and $\mathrm{T}$ if country $i$ is exposed to intervention. The effect of intervention for country $i$ can be defined as

$$
\alpha_{i t}=Y_{i t}^{I}-Y_{i t}^{N}
$$

Let $\mathrm{D}_{\text {it }}$ be a dummy variable where

$\mathrm{D}_{\mathrm{it}}=1$ if $i=1$ and $\mathrm{t}>_{\mathrm{T} 0}$ and 0 otherwise.

Then, the observed outcome for country $i$ is as follows:

$$
Y_{i t}^{I}=Y_{i t}^{N}+\alpha_{\mathrm{it}} \mathrm{D}_{\mathrm{it}}
$$

The aim of the model is to estimate $\alpha_{1 \mathrm{TO}+1}, \ldots . ., \alpha_{1 \mathrm{~T}}$. We assume that intervention takes place in country 1 . Because we know the value of $Y_{1 t}^{I}$, we will estimate $Y_{1 t}^{N}$ using the following factor model:

$$
Y_{i t}^{N}=\delta_{\mathrm{t}}+\theta_{\mathrm{t}} Z_{\mathrm{i}}+\lambda_{\mathrm{t}} \mu_{\mathrm{i}}+\varepsilon_{\mathrm{it}}
$$

$\delta_{\mathrm{t}}$ is an unknown common factor with constant factor loadings across countries, $Z_{\mathrm{i}}$ is a vector of observed covariates which are not affected by the intervention, $\theta_{\mathrm{t}}$ is a vector of unknown parameters, $\lambda_{\mathrm{t}}$ is a vector of unobserved common factors, $\mu_{\mathrm{i}}$ is a vector of unknown factor loadings and $\varepsilon_{\mathrm{it}}$ is the error term. $\mathrm{W}=\left(w_{2}, \ldots \ldots w_{j+1}\right)$ is the vector of weights where $w_{2}+w_{3}+\ldots \ldots \ldots+w_{j+1}=1$.

Each $\mathrm{W}$ represents a synthetic control and the value of the outcome for each synthetic control vector is defined as:

$$
\sum_{j=2}^{j+1} w_{j} Y_{j t}=\delta_{t}+\theta_{t} \sum_{j=2}^{j+1} w_{j} Z_{j t}+\lambda_{t} \sum_{j=2}^{j+1} w_{j} \mu_{j t}+\sum_{j=2}^{j+1} w_{j} \varepsilon_{j t}
$$

A particular $\mathrm{W}^{*}=\left(w^{*}, \ldots \ldots w^{*}{ }_{j+1}\right)$ is determined so that the difference between the pre-intervention characteristics of the treated unit and a synthetic control is minimized. In particular, $\mathrm{X}_{1}$ is the $k \times 1$ vector of the pre-intervention characteristics of the treated unit, and $\mathrm{X}_{0}$ is the $k \times J$ matrix of the same variables for the control countries. Following Abadie et al. (2010) $\mathrm{W}^{*}$ is the value of $\mathrm{W}$ that minimizes:

$$
\sum_{m=1}^{k} v_{m}\left(X_{1 m}-W X_{0 m}\right)^{2}
$$

where $v_{m}$ is the weight assigned to the $\mathrm{m}^{\text {th }}$ variable.

The outcome for the synthetic control at period $t$ is estimated as below:

$$
W^{*} Y_{0 t}=\sum_{j=2}^{j+1} w_{j}^{*} y_{j t}
$$

